\title{
AURICULO-VENTRICULAR RHYTHM
}

\author{
BY
}

R. A. MILLER

Received March 20, 1944

Auriculo-ventricular rhythm is a relatively uncommon and obscure disorder of the heart beat, only diagnosed by means of the electrocardiogram. It occurs when the A-V node assumes control over the ventricles. When this happens, two types of auriculo-ventricular rhythm may arise. One is called A-V nodal rhythm and is recognized by the inverted $P$ waves, which are as a rule either abnormally close to the QRS complex or may follow it. The second type of auriculo-ventricular rhythm is known as A-V dissociation, characterized by the rate of the ventricular contractions being slightly faster than those of the auricles so that there is no constant $\mathbf{P}-\mathbf{R}$ or $\mathbf{R}-\mathbf{P}$ interval. Theoretically, the difference between the two rhythms is due to retrograde conduction being present in $\mathrm{A}-\mathrm{V}$ nodal rhythm in order to allow the auricles as well as the ventricles to respond to the new pace-maker in the A-V node, while in $\mathrm{A}-\mathrm{V}$ dissociation retrograde conduction from $\mathrm{A}-\mathrm{V}$ node is blocked so that the auricular contractions must arise above the A-V node, probably in the sino-auricular node (Cutts, 1937; Richardson, 1922). When ventricular bigeminy complicates A-V rhythm it is described as ventricular interference: as reciprocal rhythm when it occurs with $A-V$ nodal rhythm, and as pseudo-reciprocal rhythm when it accompanies A-V dissociation.

To obtain a fuller understanding of these rhythms a record of thirteen such cases will be given and their unusual features will be discussed under the following headings: contributions to ætiology, the mode of onset of A-V rhythm, the significance of associated symptoms, and the value of tests used in differentiating the underlying mechanism of the disorder. Before entering upon any discussion or drawing any conclusions upon the present work, a brief account of the salient features of six of the present series of cases will be related.

\section{CASE Histories}

Case 1.--Mr. S. C., aged 20, had subacute rheumatic fever and exhibited nodal rhythm for at least four months, $15 / 10 / 41$ to $5 / 2 / 42$. The disorder was associated with aortic and mitral disease, and exercise, atropine, and vagal stimulation were all able to produce normal sinus rhythm. The exercise consisted of doing $9512 \mathrm{ft}$.-lb. work in two minutes. The dose of atropine was $1 / 30$ of a grain given intravenously. The result of the vagal pressure test is recorded in Fig. 1. This shows nodal rhythm,

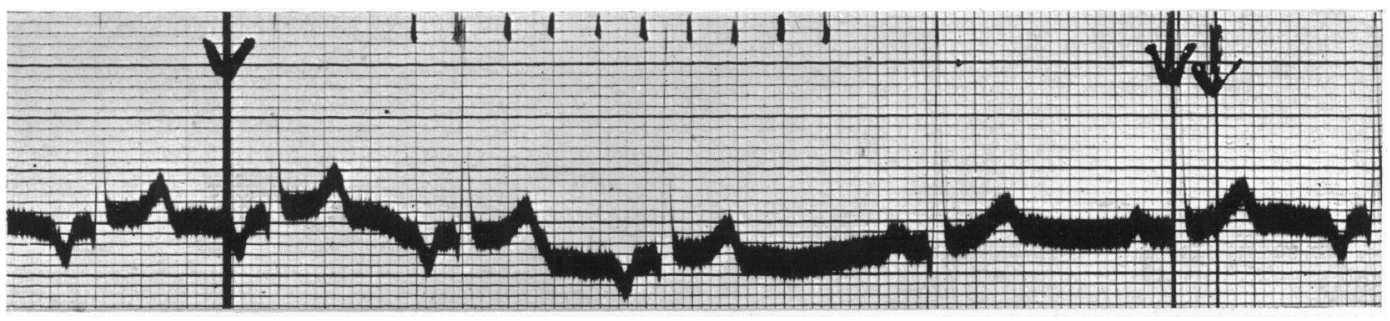

FIG. 1.-Case 1. Nodal rhythm changing to normal sinus rhythm by means of carotid sinus pressure, which was maintained between the single thick vertical line and the double thick vertical lines, marked with arrows. The time-marker shows $1 / 5$ and $1 / 25 \mathrm{sec}$. 
rate 80 , followed by normal sinus rhythm when the heart rate had fallen to 50 beats a minute. This change occurred after the application of vagal pressure which is indicated by a thick vertical line. Immediately vagal pressure is removed (denoted by a pair of thick vertical lines) the heart rate rises and the nodal rhythm reappears.

Case 2.-Mrs. M. J., aged 42, came under observation because of faints. Clinically, however, there was no evidence of organic disease, nor did her electrocardiogram (Fig. 2A) signify any cardiac

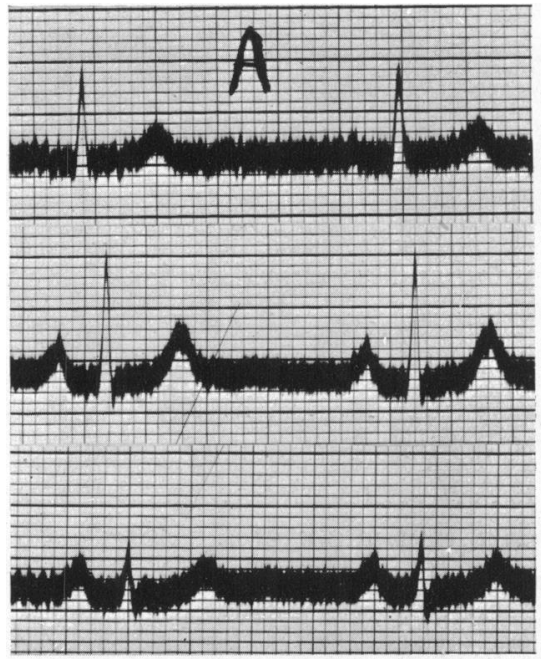

FIG. 2.-Case 2. (A) Normal sinus rhythm.

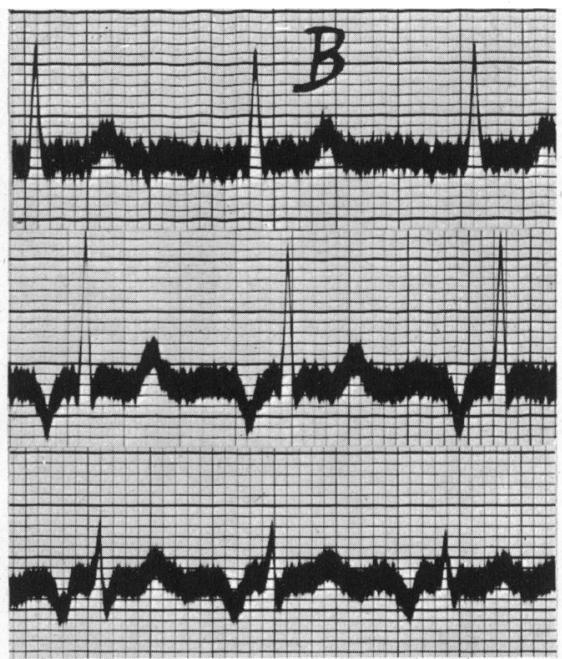

(B) A-V rhythm after exercise.

lesion. The same day she did $4694 \mathrm{ft} .-1 \mathrm{~b}$. work in two minutes and temporarily developed nodal rhythm (Fig. 2B).

Case 3.-Mr. A. F., aged 57, was admitted to hospital on 19/1/40 with essential hypertension and congestive heart failure. At first he had normal sinus rhythm, but later it was converted to A-V dissociation with digitalis therapy. When A-V dissociation was present on 6/2/40 and 16/11/40 the patient was nauseated with digitalis and the drug was withheld while the action of intravenous atropine, 1/50-1/30 grain, was studied on. five occasions. In no instance did atropine abolish the abnormal rhythm, but on each occasion the rhythm was complicated by intermittent ventricular bigeminy (Fig. 3A) 62-90 seconds after the injection, and it lasted approximately 22-27 seconds.

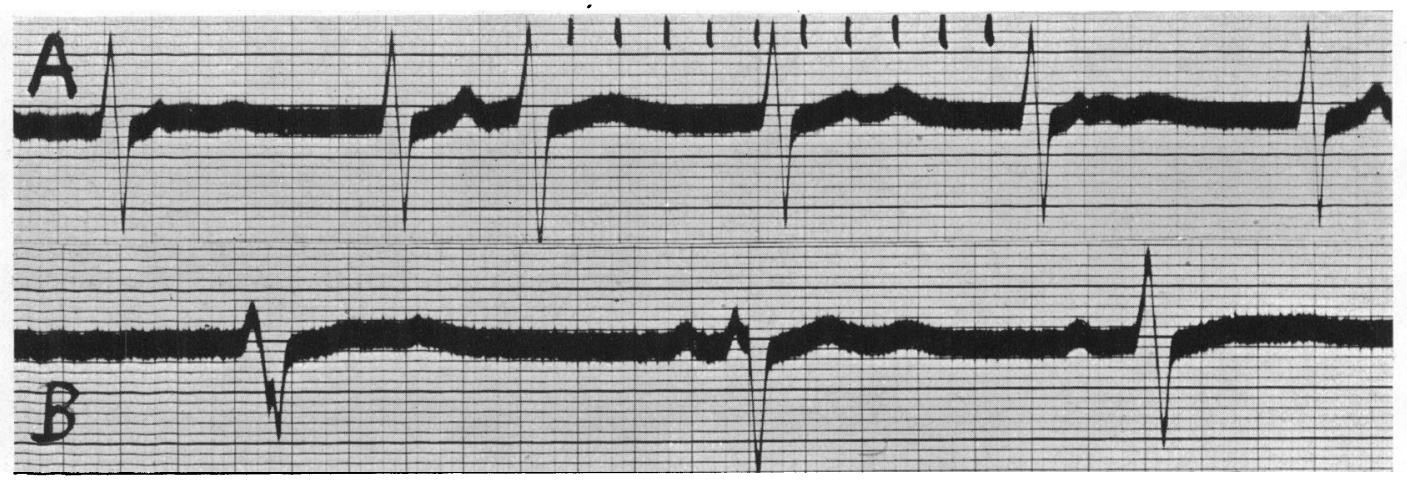

FIG. 3.-Case 3. (A) A-V dissociation with intermittent ventricular bigeminy due to atropine administration. (B) A-V rhythm with three distinctive ventricular complexes.

During this period the ventricular rate was 43-54 beats a minute It was also noted that there were three ventricular rhythms characterized by their three distinctive QRS complexes and by their inherent rates of $35.8,41 \cdot 7$ and 37.5 (Fig. 3B), but it was only the last one that was associated with ventricular bigeminy.

Case 4.-Mr. W. B., aged 49, demonstrates how either exercise or atropine abolishes auriculoventricular rhythm in an apparently healthy man who probably had the cardiac disorder for 25 years. He had complained of palpitation since he was nine years old and owing to D.A.H. he was discharged 
from the Army during the 1914-18 war. At the time of the present observations he still had palpitation and was unduly short of breath on exertion. On examination in 1942 he was a plethoric type of man, but otherwise fit. Electrocardiographically he had nodal rhythm which slowed two or three beats a minute with either right or left carotid sinus pressure. Exercise, amounting to $9861 \mathrm{ft}$.-lb. work in two minutes raised the heart rate from 65 to 93 and at the same time normal sinus rhythm appeared. Intravenous atropine, 1/30 grain, had the same effect as the exercise test.

Case 5.-Miss M. R., aged 7, was physically fit, but clinically and radiologically there was evidence of a congenital heart with a septal defect. She was proved to have auriculo-ventricular rhythm of long standing, but normal sinus rhythm and sino-auricular block temporarily interrupted it. She was examined on seven occasions when her dominant rhythm was auriculo-ventricular complicated by ventricular bigeminy (Fig. 4A). The latter appeared when the ventricular rate ranged from 42 to 56 provided the Q-P interval was over 0.24 second.

The reaction of the abnormal rhythm to an augmented heart rate was to produce normal sinus

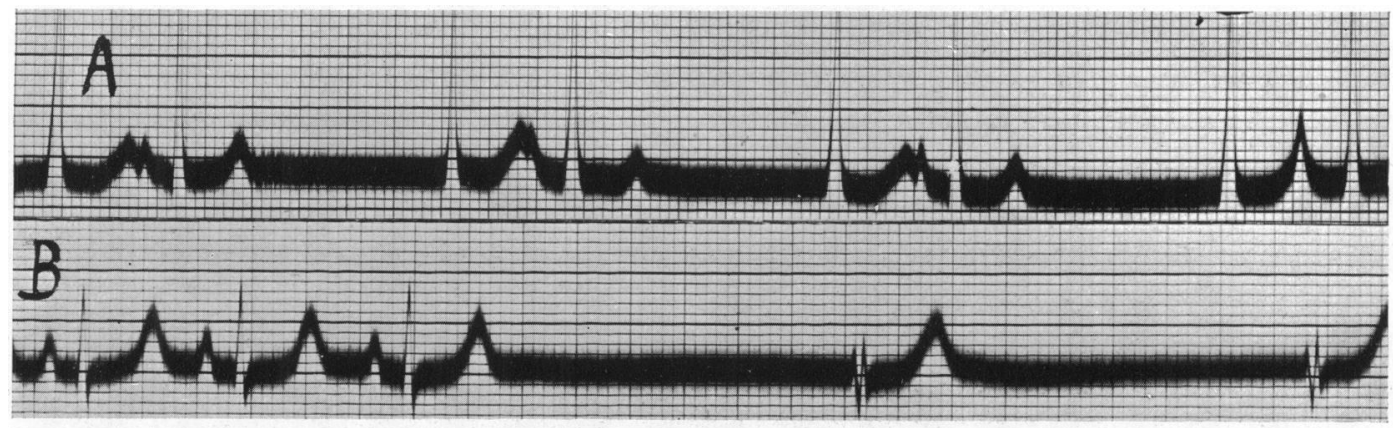

FIG. 4.-Case 5. (A) Auriculo-ventricular rhythm with ventricular bigeminy. (B) After physical exercise she developed normal sinus rhythm which was terminated by sino-auricular block and A-V rhythm.

rhythm ; this was done on $6 / 6 / 41$, after the patient had performed $2188 \mathrm{ft} .-1 b$. work in two minutes : the transformation was again affected on $9 / 6 / 41$ by injecting atropine sulphate, $1 / 100$ grain, intravenously. It was strange that with the exercise test the maximum rate was not recorded immediately after the work for it rose from 64 to 108 after resting twelve and a half minutes. Yet another phenomenon occurred at this point; the normal sinus rhythm was periodically interrupted by sinoauricular block, which in turn was terminated by an idio-ventricular beat that continued to recur rhythmically for a short period at the rate of 36 to produce nodal rhythm (Fig. 4B).

Vagal stimulation did not alter the auriculo-ventricular rhythm except on one occasion when the auricular rate fell 9 beats a minute.

Case 6.-Mr. K. G., aged 25, was an apparently healthy man who for the past eight weeks had suffered from attacks of faintness and dizziness while blowing his bugle. On examination no physical abnormality was discovered. His electrocardiogram (Fig. 5) revealed normal sinus rhythm

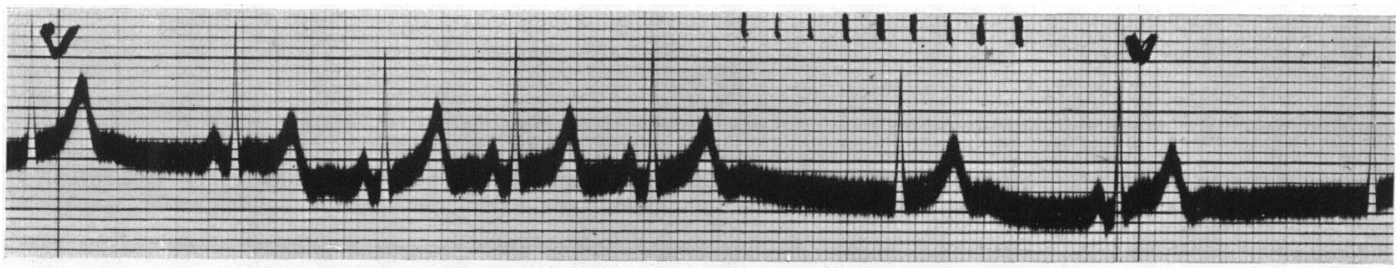

FIG. 5.-Case 6. Normal sinus rhythm during inspiration (marked by the thick vertical line and arrow) and A-V dissociation with expiration (marked by the second thick vertical lines and arrow).

with a heart rate of 75 following inspiration (indicated by thick vertical line), but with full expiration A-V dissociation occurred when the heart rate fell to 43 (indicated by the second thick vertical line). When exercise or atropine was given to this patient this abnormality was abolished, although sinus arrhythmia was exceptionally prominent.

\section{ÆTIOLOGY}

Both nodal rhythm and auriculo-ventricular dissociation arise through either a depression or destruction of the S-A node or else by enhancing the activity of the A-V node. Other times these factors act collectively: Such changes can be brought about by an alteration in vagal 
tone (Bishop, 1921; Cutts, 1937; Gallavardin, 1920; Goodman, 1930; Resnik, 1925; Weiss, 1933), degenerative processes (Cowan, 1939), infective agents (Cutts, 1937; Reid, 1930), and by the administration of atropine, digitalis, and other drugs (Hewlett, 1923; Zeisler, 1932). The rhythm defect, however, may be missed unless exercise is given prior to the electrocardiographic investigation (Case 2).

When ventricular bigeminy complicates the A-V rhythm, the pathology and precipitating factors are similar (Bain, 1939; Bishop, 1921; Blumgart, 1930; Cowan, 1939; Cutts, 1937; Jones, 1927; Katz, 1938; Luten, 1932; and Reid, 1930; also Cases 1, 2, and 5) except that it has not been observed after exercise or with general anæsthesia (Kurtz, 1936). Doubt as to its existence in the dying heart and with asphyxia associated with Cheyne-Stokes breathing also prevails, but, in the former, A-V rhythm may be.interrupted by ectopic beats with or without a compensatory pause (Sigler, 1937; Turner, 1931).

When atropine is responsible for $\mathrm{A}-\mathrm{V}$ rhythm the rate may range from 52 to 100 and it may persist while the heart accelerates (Table I). The figures are obtained by taking electrocardiographic records of nine people before, during and after the intravenous injection of atropine sulphate, 1/30 grain. As intermittent observations were made after the drug had been given, the onset and termination of A-V rhythm was not always accurately known. Nevertheless, it will be seen from Table I that the rate of A-V dissociation at some time of its existence was greater than the initial heart rate. This suggests that the rhythm disorder can occur while the heart rate is augmented. This is demonstrated more conclusively in five cases $(3,6,7,8$, and 9$)$ where $\mathrm{A}-\mathrm{V}$ dissociation was recorded while the heart rate was increasing. Such behaviour cannot be said to be due to superimposed organic disease for the disorder sometimes occurred in apparently normal subjects and because normal sinus rhythm always developed with the maximum heart rate.

TABLE I

A-V Dissociation due to Atropine Administration

\begin{tabular}{|c|c|c|c|c|c|}
\hline Case No. & Date & Remarks & & $\begin{array}{l}\text { Ventricular rate } \\
\text { with N.S.R. }\end{array}$ & $\begin{array}{l}\text { Ventricular rate } \\
\text { with dissociation }\end{array}$ \\
\hline $\begin{array}{r}3 \\
3 \\
6 \\
7 \\
8 \\
8 \\
9 \\
9 \\
10 \\
11 \\
12 \\
13\end{array}$ & $\begin{array}{r}4 / 3 / 40 \\
26 / 11 / 40 \\
25 / 3 / 41 \\
5 / 9 / 40 \\
7 / 6 / 40 \\
10 / 6 / 40 \\
27 / 2 / 40 \\
5 / 3 / 40 \\
1 / 8 / 40 \\
25 / 9 / 41 \\
16 / 9 / 40 \\
8 / 11 / 41\end{array}$ & 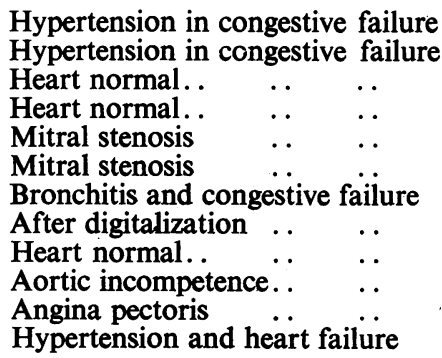 & 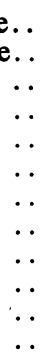 & $\begin{array}{l}37-60 \\
37-56 \\
57-95 \\
79-120 \\
48-57 \\
47-60 \\
79-94 \\
88-120 \\
60-88 \\
62-88 \\
66-94 \\
75-115\end{array}$ & $\begin{array}{l}55 \\
52-56 \\
57-83 \\
93-96 \\
54-55 \\
54-60 \\
79-94 \\
88-98 \\
70 \\
75 \\
79 \\
100\end{array}$ \\
\hline
\end{tabular}

Therefore, in the present series of cases, atropine probably acted more rapidly upon the auriculo-ventricular node than on the sino-auricular node, so as to allow the ventricles to beat faster than the auricles and at the same time to permit both auricle and ventricles to increase their rates. This view on the dual action of atropine is not shared by Wilson (1915) who believed that A-V dissociation due to atropine was due to an initial "inverse" excitation of the vagus which was followed by the later paralytic effect.

\section{MODE OF ONSET}

It is generally believed that the transition from normal sinus rhythm to auriculo-ventricular rhythm takes place without the cognizance of the patient or doctor, for no characteristic signs or symptoms are produced. Nevertheless, suspicion of its development should be aroused 
by the onset of a bradycardia. As a rule, the alteration in rhythm is accompanied by a gradual slowing of the heart rate, but in Case 5 there was an abrupt fall in the heart rate from 96 to 36 beats a minute, the change being due to normal sinus rhythm being terminated by S-A block which was followed by an A-V rhythm with a ventricular rate of 36 . A similar sequence of events has been described by Weiss and Baker (1933) in their Cases 1 and 2. They achieved the transformation in rhythm by applying carotid sinus pressure to their patients. Therefore, it is probable that alteration in vagal tone explains the change in Case 5 as well as in those mentioned by Weiss and Baker (1933).

The factors that account for ventricular bigeminy being intermittent in A-V rhythm are the rate of the heart and the refractory period of the A-V node and bundle. The latter is determined by measuring the Q-P intervals, or the time which elapses between the initial deflexion of the QRS complex and the beginning of the P wave. The shortest Q-P interval when ventricular bigeminy is present and the longest Q-P interval when the extra beat is absent, are the two important measurements, as it is somewhere between them that the refractory period lies. Details of these investigations are given on Table II and in the history of Cases 3 and 5. They may be summarized by stating firstly that a bradycardia is almost certainly essential for the development of ventricular bigeminy. Secondly, the ventricular rates during which the bigeminy appears will vary from case to case. Thirdly bigeminy is controlled by the refractory period of the A-V node and bundle. It is also clear that an increase in the heart rate is accompanied by a diminution in the refractory period which is analogus to reduction in the $\mathrm{P}-\mathrm{R}$ interval when the heart rate is augmented in some people with partial heart block.

TABLE II

Influence of Heart Rate and Q-P INTERval upon Ventricular Bigeminy

\begin{tabular}{|c|c|c|c|c|}
\hline Case No. & Date & $\begin{array}{c}\text { Ventricular rate } \\
\text { per minute }\end{array}$ & $\begin{array}{c}\text { Shortest Q-P interval } \\
\text { with bigeminy, } \\
\text { seconds }\end{array}$ & $\begin{array}{l}\text { Longest Q-P interval } \\
\text { without bigeminy, } \\
\text { seconds }\end{array}$ \\
\hline $\begin{array}{lcc}\text { Blumgart (Case 2).. } & \\
\text { Case 3 } & \ldots & \ldots \\
\text { Case 3 } & \ldots & \ldots \\
\text { Case 5 } & \ldots & \ldots \\
\text { Case 3 } & \ldots & \ldots \\
\text { Case 3 } & . . & \ldots\end{array}$ & $\begin{array}{l}1930 \\
13 / 2 / 40 \\
8 / 2 / 40 \\
6 / 6 / 41 \\
6 / 2 / 40 \\
8 / 2 / 40\end{array}$ & $\begin{array}{c}60 \cdot 0 \\
55 \cdot 5 \\
47 \cdot 6 \\
45-48 \\
44 \cdot 1 \\
42 \cdot 2\end{array}$ & $\begin{array}{l}0 \cdot 36 \\
0 \cdot 32 \\
0 \cdot 37 \\
0 \cdot 34 \\
0 \cdot 40 \\
0 \cdot 46\end{array}$ & $\begin{array}{l}0 \cdot 32 \\
0 \cdot 30 \\
0 \cdot 35 \\
0 \cdot 32 \\
0 \cdot 40 \\
0 \cdot 46\end{array}$ \\
\hline
\end{tabular}

It is now evident that ventricular bigeminy must have a complex mechanism and it probably arises through the stimulus that activates the auricle passing backwards to re-enter the ventricle to produce an extra ventricular contraction. This sequence of events is known as " re-entry" and it is preferred by most authors to the alternative theory of "parasystole." The latter is based on the supposition that there is a second automatic centre situated low down in the auricle which initiates the extra ventricular contraction (Blumgart, 1930, and Luten, 1932).

\section{SigNIFICANCE OF SyMPTOMS}

It is uncommon for A-V rhythm to produce symptoms; palpitation, however, is sometimes reported (Cowan, 1935; Schotts, 1937; and Thomson, 1941), and it may be associated with ventricular bigeminy (Case 4). At other times faintness and giddiness occur (Katz, 1938, and Case 6) and they. are probably due to the accompanying bradycardia that develops suddenly without an adequate compensatory mechanism in the cerebral or the systemic circulation. Such an explanation has been offered for similar symptoms in a person who developed a sudden 
bradycardia while normal sinus rhythm was present (Turner, 1931). The prognosis in these cases is the same as for any other symptom experienced during A-V rhythm. That is to say, prognosis is determined entirely by the associated pathological process and not by the abnormal rhythm (Richardson, 1922).

\section{The Value of Tests in Detecting the Defective Mechanism}

Three tests have been utilized in an attempt to discover whether or not the A-V conducting tissue is defective. These tests have been developed on the assumption that acceleration of the heart tends to increase metabolic disturbances that may accentuate or reveal abnormal rhythm or conduction, while slowing the heart rate will have the opposite effect. The tests involve the use of atropine, exercise, and vagal stimulation, and are simple to perform. Unfortunately, their value is very limited on account of both vagal dysfunction and organic disease of the cardiac conducting mechanism being sometimes present (Cases 1 and 3). At other times, technical errors, such as failure to repeat a test with greater vigour or with larger doses of atropine in people with persistent $\mathrm{A}-\mathrm{V}$ rhythm may give rise to fallacies.

The vagal stimulation test is performed by pressure on the carotid sinus. Normally, a heart can react in numerous ways to such a procedure. Moreover, if an alteration in rhythm is produced it cannot always be reproduced (Weiss, 1934). When vagal stimulation is utilized in the investigation of $\mathrm{A}-\mathrm{V}$ rhythm, there are two responses that are informative; in one $\mathrm{A}-\mathrm{V}$ rhythm persists throughout the test and is indicative of either vagal dysfunction or a cardiac lesion as the ætiological factor of the rhythm disorder (Blumgart, 1930; Dock, 1928; Luten, 1932; Thomson, 1941; Wedd, 1930; White, 1915; and Cases 4 and 9). In the other response, normal sinus rhythm develops, from which it may be concluded that organic disease of the heart is present. As far as is known, Case 1 is the only example exhibiting these features, but as he had aortic and mitral disease, the test did not aid in the prognosis and treatment of this patient. Therefore, it may be concluded from the above evidence that vagal stimulation is of little or no value in investigating A-V rhythm.

The two tests that are likely to prove of value in A-V rhythm are the exercise test and the atropine test. The former consists of making the patient do so many foot-pounds of work in a given time, while the latter is done by giving atropine, 1/60-1/20 grain, orally or subcutaneously, or intravenously (Bokspan, 1928; Goodman, 1930; Katz, 1938; Luten, 1932 ; Neslin, 1932; Ritchie, 1923; Wedd, 1941; White, 1915; and Cases 1, 3, 5, and 13). These tests are, however, only warranted or enlightening when the ætiology of A-V rhythm is obscure. In view of this, six apparently healthy people with A-V rhythm (Bishop, 1921; Cutts, 1937; Thomson, 1941; Williams, 1913; and Cases 4 and 6) have been studied, and it has been found that atropine abolished the abnormal rhythm in all but one instance (Williams, 1913). Therefore, the majority exhibited vagal dysfunction, which carries with it a good prognosis. This is even true should the abnormal rhythm be present for eighteen months (Thomson's Case 1, 1941) or possibly twenty years (Case 4). When organic disease is the determining factor in the production of A-V rhythm the expectation of dife can not be as good, but it is possible for the rhythm disorder to persist for a year and for health to be maintained over the corresponding period of time (Williams, 1913).

\section{SUMMARY}

This paper is based on observations on thirteen cases of auriculo-ventricular rhythm, the salient features of which have been correlated with appropriate facts recorded by others. The outstanding features fall under four headings as follows.

Physical exercise may now be added to the factors that precipitate A-V rhythm. Atropine can produce the rhythm disorder when a tachycardia is present, or when the heart rate is increasing. From these observations it was decided that atropine acted simultaneously and 
unequally upon the sino-auricular node and the auriculo-ventricular node in order to produce A-V rhythm.

As a rule, the onset of A-V rhythm cannot be detected by the patient or the physician. Sometimes, however, the patient may complain of giddiness, weakness, or palpitation, and the doctor may note an abrupt fall in the pulse rate. An explanation for these symptoms and signs has been given.

Should A-V rhythm be complicated by ventricular bigeminy, it is generally transitory, but it may be intermittent for months, the onset of bigeminy being partially determined by the length of the Q-P interval and by the site of origin of the ventricular contraction. It should be-noted, however, that the critical Q-P interval, below which ventricular bigeminy ceases to appear, varies with the rate of the heart.

The prognosis for people with $\mathrm{A}-\mathrm{V}$ rhythm is influenced and controlled by systemic disturbances and cardiac disease. The detection of the latter is sometimes possible by utilizing the following tests: vagal pressure, exercise, and atropine, provided such tests are performed and interpreted cautiously. These tests are only warranted when the ætiology of A-V rhythm is obscure. Six such cases have been reviewed. One proved to be due to organic disease and the others to vagal dysfunction. In the former there was no deterioration in health over a period of one year, although the disorder persisted for this period. In those people with abnormal vagal tone as the ætiological factor, it is probably possible to lead an active life for 25 years with intermittent $\mathrm{A}-\mathrm{V}$ rhythm.

This study was carried out under the auspices of The Kirk Duncanson Research Fellowship in Medicine. Assista nce and guidance was received from Dr. Rae Gilchrist who permitted me to make the observations upon his patients in The Royal Infirmary, Edinburgh. Expenses of the electrocardiographic records was covered by a grant from the Moray Endowment Fund. In conclusion, I would like to express my gratitude for all this assistance and to thank the nursing and technical staff for their co-operation.

\section{REFERENCES}

Bain, V. W. C. (1939). Lancet, 1, 20.

Barlow, P. (1927). Ibid., 1, 65.

Bishop (1921). J. Amer. med. Ass., 77, 31.

Blumgart, H. L., and Gargill, L. (1930). Amer. Heart J., 5, 424.

Bokspan, N. (1928). Arch. Mal. Caur, 21, 802.

Cowan, J., and Ritchie, W. T. (1935). Diseases of the Heart, 3rd ed., London, p. 85.

- (1939). Brit. Heart J., 1, 18-31.

Cutts, F. B. (1937). Amer. Heart J., 13, 451, and 14, 717.

Dock, W. (1928). Arch. intern. Med., 41, 745.

Gallavardin, L., and Duma, A. (1920). Arch. Mal. Cour., 13, 63.

Goodman, M., and de Graff, A. C. (1930). Amer. Heart J., 5, 375.

Hewlett (1923). Heart, 10, 9.

Jones, T. D., and White, P. D. (1927). Amer. Heart J., 2, 266.

Katz, L. N., and Kaplin, L. G. (1938). Ibid., 16, 694.

Kurtz, C. M., Bennet, J. H., and Shapiro, H. H. (1936). J. Amer. med. Ass., 106, 434.

Luten and Jensen (1932). Amer. Heart J., 7, 593.

Neslin, W., and Ettinger, I. (1932). Deutsches Arch: Klin. Med., 173, 212.

Reid, W. D. (1930). Amer. Heart J., 5, 525.

Resnik and Lathrop (1925). Arch. intern. Med., 36, 229.

Richardson (1922). Ibid., 29, 253.

Ritchie, W. T. (1923). Edin. med. J., 2n'd Series, 30, 621.

Schotts, A. (1937). Amer. Heart J., 13, 61.

Sigler, L. H., Stein, I., and Nash, P. I. (1937). Amer. J. med. Sci., 194, 356.

Smith, C. S. (1921). Ibid., 162, 575.

Thomson, W. B. (1941). Atrio-Ventricular Nodal Rhythm, Atrio-Ventricular Dissociation, and Reciprocal Rhythm. M. D. Thesis, Edinburgh.

Turner, K. B. (1931). Amer. Heart J., 6, 743.

Wedd, A. M. (1930). Ibid., 5, 493.

(1941). Amer. J. Dis. Child., 62, 154.

Weiss, S., and Baker, J. P. (1933). Medicine, 12, 297.

- and Ferris, E. B. (1934). Arch. intern. Med., 54, 931.

White, P. D. (1915). Ibid., 16, 517.

Williams, N. B., and James, H. (1913-14). Heart, 5, 109.

Wilson, F. M. (1915). Arch. intern. Med., 16, 86 and 989.

Zeisler (1932). Journ. Lab. Clin. Med., 18, 225. 